\title{
Improvement of the method for producing confitures
}

\author{
Andreii Zahorulko*, Aleksey Zagorulko, Bogdan Liashenko, and Irina Gordienko \\ Kharkiv State University of Food Technology and Trade, 61051, Kharkiv, Ukraine
}

\begin{abstract}
The method for the production of confiture has been improved, which consists in preliminary infrared processing of fruits and vegetables by drying at a temperature of $45 \ldots 50{ }^{\circ} \mathrm{C}$, followed by grinding them to $1.5 \ldots 2.5 \mathrm{~mm}$. Introduction of inverted syrup (to prevent sugar crystallization during storage of confitures), and subsequent boiling to a dry matter content of $60 \ldots 76 \%$ at a temperature of $45 \ldots 50{ }^{\circ} \mathrm{C}$, which makes it possible to obtain confitures with high organoleptic characteristics. The obtained confiture is characterized by a high biological value and quality due to the increase of vitamins and microelements in it due to the use of fruit and berry raw materials and providing a gentle heat and mass exchange treatment at all stages of production.
\end{abstract}

Keywords: confitures, food production, method for producing confitures

\section{Introduction}

The growing volume of food products in the form of high-viscosity concentrated products is determined by their obvious advantages [1]. Such products are compact, do not require a large number of containers, and the unit costs for their transportation are minimal. The manufacturing processes for such products can be low-waste. Concentrated food products based on fruit and vegetable raw materials [2], as a rule, have a long shelf life - from 6 to 15 months or more, which is explained by the high content of dry matter and the presence of organic acids. Progressive processes for the production of highly concentrated fruit and vegetable products make it possible to preserve most of the biologically active substances in them.

Currently, there is a significant range of concentrated food products obtained using fruit and vegetable raw materials [3-6]. These include fruit and berry purees, pastes, sauces, baby food cans, fruit and berry jelly, jam, marmalade, marshmallow, preserves, candied fruits, confitures, drink concentrates, etc. [7-8].

Analysis of literature data showed that the production of dry confitures is one of the most promising productions of high-viscosity concentrated products.

However, all existing methods for the production of confitures have the disadvantage that the resulting products have a low level of nutritional value, due to the large loss of biologically active substances (BAS) during processing and, as our research has shown, have a high cost price. Therefore, it is advisable to develop low-waste resource-saving

* Corresponding author: panamari73@gmail.com 
methods for producing inexpensive confitures using natural raw materials and allowing the content of biologically active substances to be preserved in the final product.

\section{Experimental}

At the Kharkov State University of Food Technology and Trade, a new effective resourcesaving technology for the production of "dry confitures" has been developed and research has been carried out to improve the processes and equipment for their production.

The existing technology for the production of confiture is that the fruit for the production of confiture is prepared, sorted, washed and cleaned. In stone fruits, the seeds and stalks must be removed. In pome fruits, the skin, seed nest, stalks are removed and flesh is cut into slices or pieces. Confiture cooking is carried out in vacuum apparatus or double-chamber boilers at a heating steam pressure of $150 \ldots 300 \mathrm{kPa}$. Sugar syrup is put into the boiling apparatus, brought to a boil, after which the prepared fruit is added and boiled for $15 . . .20$ minutes with stirring. Then molasses and pectin are added into the boiling product and tartaric acid $2 . . .3$ minutes before the end of cooking. The cooking time is about 25 minutes. Cooked confiture is cooled to $80 \ldots 85^{\circ} \mathrm{C}$ and packaged into jars.

The disadvantages of this method include the high boiling temperature of the confitures, which significantly reduces the amount of biologically active substances and reduces the nutritional value of the final product. Also, the disadvantage is that sugar crystallization is observed during the storage of ready-made confitures.

The improved method uses the approach of gentle temperature modes of concentration and the use of inverted syrup in the recipe, which provides an increase in the biological value and taste, prevention of sugar crystallization during storage, conservation of energy resources and a decrease in the duration of confiture production.

The proposed method is generally carried out as follows. Fresh fruits or vegetables are inspected, washed and then infrared dried. The drying process is carried out at a temperature of $45 \ldots 50{ }^{\circ} \mathrm{C}$ until the dry matter content in fruit and vegetable raw materials is $30 . . .40 \%$ in a universal infrared dryer. Then the dried raw materials are ground in a grinder to a particle size of $1.5 \ldots .2 .5 \mathrm{~mm}$ with further mixing with inverted sugar syrup (to prevent sugar crystallization during the storage of confitures), citric acid and aromatic components. The concentration of the resulting mass is carried out at a temperature of $45 \ldots 50{ }^{\circ} \mathrm{C}$ using a vacuum evaporator to a dry matter content of $60 \ldots 76 \%$, within $5 \ldots 10$ minutes until a homogeneous consistency, pasteurized at a temperature of $70{ }^{\circ} \mathrm{C}$ and then the obtained dry confitures are packed into jars.

The obtained confitures have solid consistency, pleasant taste, color, high organoleptic characteristics, nutritional and biological value. The use of the proposed method allows to significantly increase the biological value and taste of the finished confiture due to the higher levels of vitamins and microelements in it, as well as to significantly reduce the technological costs in the process of preparing the confitures by the proposed method.

To implement the confiture concentration process, a constructive and technological solution of a vacuum evaporator is proposed to increase the heat exchange surface and modernize the stirring machine design. In addition, the replacement of the steam jacket with modern electric heaters is provided.

The improvement of the design model of a vacuum evaporator with an increased heat exchange surface has a working process tank 1 (Fig. 1), which is heated by a flexible film resistive radiating-type electric heater with a heat-insulating outer surface 2 (RFFREH). The use of an electric heater does not require additional use of steam, the presence of any heating shells, pipelines and heat generators. The cover of the apparatus 3 has a standard control and safety valve 4 , installed in the basic configuration of vacuum evaporators of the MZS brand, including an inspection window 5. 
The heat exchange surface increases due to the improvement of the design of the mixing device 6 by heating it with RFFREH and the placed flow dividers 7. Improvement of the mixing of the near-wall layer of the raw material during concentration was due to the use of ribs 8 . In this case, the flow dividers provide intensive mixing of the inner mass of the concentrated raw material. Electric supply to the heater of the stirring machine 6 is provided by the hollow inner space and the contact platform 9 located in the upper part of the apparatus. The proposed constructive solution made it possible to increase the useful heat exchange surface by $0.5 \mathrm{~m}^{3}$.

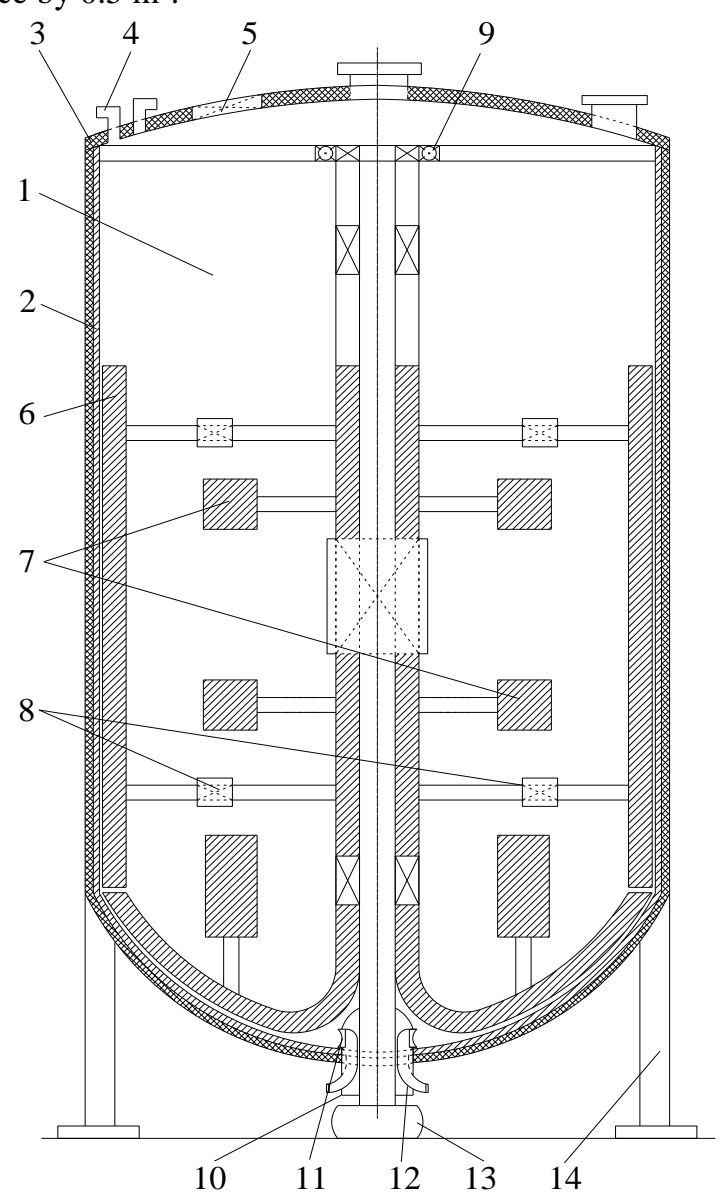

Fig. 1. Design of the improved vacuum evaporator: 1 - working process tank; 2 - flexible film resistive heater of emitting type with heat-insulating outer surface (RFFREH) 3 - apparatus cover; 4 control and safety valves; 5 - inspection hatch; 6 - improved mixing device; 7 flow dividers; 8 spring-loaded ribs; 9 - RFFREH contact platform; 10 - discharge pipe; 11 - automatic shut-off valve; 12 - guides for product removal; 13 - electric drive with worm gear; 14 - racks.

The unloading of the apparatus is carried out by an automatic branch pipe 10, mounted in the lower part, around the mixing device 6 , which ensures the automatic opening of the shut-off valve 11 . Thus, the concentrate is removed by the guides 12 for further technological operations.

The rotation of the improved mixing device 6 is carried out from an electric drive with a worm gear 13. The apparatus is placed on racks 14 . The resulting secondary steam in the process of boiling through the pipeline is supplied to the shell-and-tube condenser or is used for the technical needs of the line. The principle of implementation of the 
technological process is characteristic of the basic designs of vacuum evaporators, and the difference consists in the heating system due to an increase in the heat exchange surface and a decrease in the duration of the heat and mass transfer process.

To determine the effectiveness of the proposed constructive and technological solutions, the kinetics of confiture heating in an improved apparatus was established in comparison with the basic design of the MZS-320 (Fig. 2). The analysis of the given curves confirms the effectiveness of the proposed design and technical solutions to increase the heat exchange surface. The duration of reaching the stationary mode $\left(52{ }^{\circ} \mathrm{C}\right)$ of the improved device is $563 \mathrm{sec}$., providing a reduction in the duration of reaching the stationary mode by $30 \%$ in comparison with the analogue.

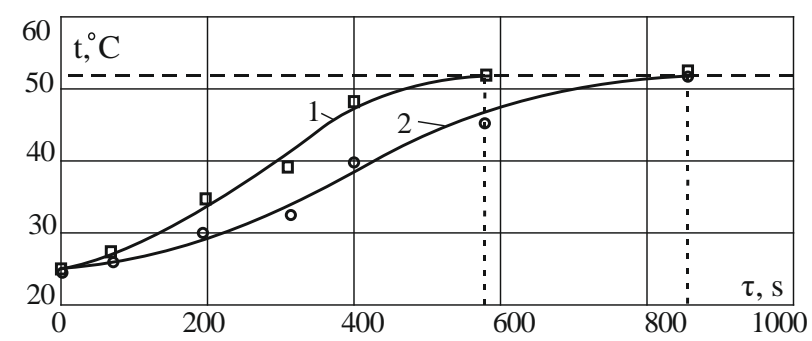

Fig. 2. Confiture heating kinetics: 1 - improved vacuum evaporator; 2 - MZS-320.

The result of the further implementation of the improved vacuum evaporator will be the improvement of the design and technological parameters of the existing lines with the concentration of natural raw materials. In addition, resource efficiency and equal effect on raw materials with smooth stabilization of the temperature field will be ensured through the use of RFFREH. Thus, ensuring the high quality of the resulting confiture and the price-toquality ratio.

\section{Conclusions}

The method for the production of confiture has been improved, which consists in preliminary infrared processing of fruits and vegetables by drying at a temperature of $45 . . .50$ ${ }^{\circ} \mathrm{C}$, followed by grinding them to $1.5 \ldots .2 .5 \mathrm{~mm}$. Introduction of inverted syrup (to prevent sugar crystallization during storage of confitures), and subsequent boiling to a dry matter content of $60 \ldots 76 \%$ at a temperature of $45 \ldots 50{ }^{\circ} \mathrm{C}$, which makes it possible to obtain confitures with high organoleptic characteristics. The obtained confiture is characterized by a high biological value and quality due to the increase of vitamins and microelements in it due to the use of fruit and berry raw materials and providing a gentle heat and mass exchange treatment at all stages of production. To implement the confiture concentration process, a constructive and technological solution of a vacuum evaporator was proposed with the replacement of the steam jacket with a modern electric heater and an increased heat exchange surface by $0.5 \mathrm{~m}^{3}$ due to the modernization of the stirring machine design.

\section{References}

1. M. Habanova, J. Saraiva, M. Holovicova, S. Moreira, M. Bronkowska, J. Gazo, M. Schwarzova, P. Chlebo, M. Bronkowsk, JFF, 60, 154 (2019)

2. M. Gustavo Hobold, Alexandre K. da Silva. Inter. J. HM Transfer, 134, 511 (2019)

3. A. O. Charles, FRI, 76, 986 (2015) 
4. F. Mackenzie J., M. Kameron J., B. Laura L., B. Alyssa J., H. John E., J. Susan L., JNEB, 53, 96 (2021)

5. A. C. Pereira Silveira, Food and Nutrition. NNT, (2015)

6. A. Elvis, I. Nidret, K. Zdravko, G. Ignacio E., K. Maziar, E, 158, 1160 (2018).

7. A. Zahorulko, A. Zagorulko, N. Fedak, S. Sabadash, D. Kazakov, V. Kolodnenko, EEJET, 6, 6-13 (2019)

8. O. Cherevko, V. Mykhaylov, A. Zahorulko, A. Zahorulko, A. Borysova, FST, 12, 50 (2018) 